\title{
Comparative Analysis of Movement Experiments Based on Computer Statistical Software and Test Technology
}

\author{
Xiuling Ou \\ Department of Physical Education, Tianjin Agricultural University, Tianjin, China \\ ou_xiuling@126.com
}

\begin{abstract}
Keywords:aerobic exercise; anaerobic exercise; weight-losing effect; experiment analysis; comparative analysis
\end{abstract}

\begin{abstract}
With the improvement of life standard and the increasing of pressure, more and more people are being fat in common life. So how to lose weight effectively becomes the very topic that many people concern commonly on. Now, many studies aimed at the effect of weight-losing under both aerobic and anaerobic exercise, but all of them is single just for one exercise. Of course, it must has something tolose weight so long as you exercise appropriately, but we pay more attention to the problem how it could be better. And this paper makes a contrastive test from both aerobic and anaerobic exercise. It applys SPSS software and the test method of U- Mann Whitney to analyze the data. Finally, the result shows that the two kinds of exercises make proper effects on reducing weight with a little differences.
\end{abstract}

\section{Introduction}

With the constant development and progress of society, people pay more attention to the life quality, and accordingly, the living standard has been improved. However, facing so much pressure of competition, people devoted themselves to their jobs, which limits the time and modes to sports, which may cause the stage of obesity[1].It is a worthy of attention in today's society. More and more people are focusing on how to achieve effective weight lose because obesity is also causing a lot of disease.

Many scholars are focus on aerobic or anaerobic exercise for the effect of weight loss, but they are based on a motion for single test research. Doing some moderate exercise will play a slimming effect, but the details of how to do will be better? While anaerobic exercise focused on physical strength and it is a part of training, aerobic exercise keeps a watchful eye on a long term for the body of each index equilibrium exercise[2]. But, anaerobic and aerobic exercise all do matter to weight lose, the difference is the degree of the change. In order to prevent the occurrence of obesity, from a healthy point of view, we need enhance long-term physical exercise, so relatively speaking, either from the time and intensity, adopting aerobic exercise is more suitable for people. But we have to do some adjustments and changes for personal physical fitness, such as for a position we can strengthen anaerobic exercise[3]. Therefore, this paper studies the effects of weight loss from the anaerobic and aerobic exercise, which can guide people to recognize the form and effect of exercise more efficiently in order to exercise effectively and lose weight healthily.

\section{The research objects and methods}

Aerobic exercise is aerobic metabolism movement, that is to say, this exercise happens when the body is under the condition of adequate supply of oxygen. The advantage is that it is able to increase oxygen intake, which can consume more body heat. This kind of exercise includes low intensity and strong rhythm and its continuous time is also relatively long, usually taking more than one hour. General aerobic exercise may be the following: jogging, swimming, dancing, shadowboxing exercise, etc.

While Anaerobic exercise is a kind of intense exercise that carries out when muscles need in "hypoxia" situation. This movement is a kind of high intensity, strong moments, usually lasts for a relatively brief period. The most common items of anaerobic exercise are throwing, weightlifting, long jump high jump and push-ups, etc. Everything is relative, so is anaerobic exercise. When doing 
anaerobic exercise, the body is in the accelerate metabolism which need to consume more energy, while the produce of energy is mainly through the metabolism of glucose, protein and fat. When the amount of exercise is not much which is aerobic exercise, the energy supply for the body is derived from aerobic metabolism of fat. But when we perform strenuous exercise which is anaerobic exercise, the body's aerobic metabolism is unable to meet this need but the anaerobic metabolism of glucose can produce large amounts of energy.

Now, select classes students to the comparative test and Class A takes the anaerobic exercise training, carrying out push-ups and vertical jump, while Class B take the water aerobic exercise, and each class has one month to carry out such activities to compare the results of the body weight and other situation before and after exercise, in order to analyze which exercise has the remarkable effects on reducing weight.

This paper uses SPSS' and U Mann Whitney's method to analyze the test data comparatively in order to verify various exercises' influence on weight-losing. SPAA first do a descriptive analysis of the every target's scope of mean and distribution, as the following formula[4]. $Z_{i}=\frac{x_{i}-\bar{x}}{S}$

The data of Class A and B is independent and belongs to the continuous random variables. And certainly, the data of Class A and $\mathrm{B}$ is $\mathrm{X}(\mathrm{x} 1, \ldots, \mathrm{xm})$ and $\mathrm{Y}(\mathrm{y} 1, \ldots, \mathrm{yn})$. We mark the test results of Class A, B as $\mathrm{W}_{\mathrm{XY}}[5]: W_{X Y}=\#\left\{\left(x_{i}, y_{j}\right): x_{i}<y_{j}, i=1,2, \ldots, m ; j=1,2, \ldots, n\right\}$

The corresponding probability and cumulative probability formula of the comparative analysis of the test results of the Class $\mathrm{A}$ and $\mathrm{B}$ as follows[6]:

$$
P\left(W_{X Y}=d\right)=t_{m, n}(d+n(n+1) / 2) /\left(\begin{array}{l}
N \\
n
\end{array}\right), \quad(\mathrm{d}=0,1, \ldots, \mathrm{mn})
$$

The measurement upper arm, abdomen, back three places such as the skinfold. By measuring the triceps muscle a shoulder and the Angle skinfold, body composition analysis to study the younster health and motion having oxygen to form the coupling effects. According to body density D formula[7]:

$\mathrm{D}=1.0931-0.00160 \mathrm{x}$ (the bottom corner skinfold + the arm skinfold);

Body fat content $=$ weight $\times$ body fat percentage $(\mathrm{F} \%)$; Body fat percentage $(\mathrm{F} \%)=4.57 /$ body density D-4.142;

To fat weight $(\mathrm{LBW})=$ weight-body fat content to fat body mass index $=$ to fat weight $(\mathrm{kg}) /$ height $(\mathrm{cm}) \times 100$;

Heart rate recovery index $=(\mathrm{S} \times \Sigma \mathrm{p} 1 \mathrm{p} 2 \mathrm{p} 3) /(\mathrm{T} \times \mathrm{p} 3)$. Type: $\mathrm{S}$ for $1000 \mathrm{~m}, \Sigma \mathrm{p} 1 \mathrm{p} 2 \mathrm{p} 3$ for three consecutive every 10 seconds at $1 \mathrm{~min}$ pulse the sum total of $1000 \mathrm{~m}$ scores for $\mathrm{T}$ to test for the third time pulse several ten seconds[8].

From the formula,S for 1000 meters, three times of uninterrupted test test the ten seconds of pulse, of which the interval of each test for 1 minute, $\mathrm{T}$ for teenagers in the 1000-meter run average scores, is the third test of pulse number 10 seconds.

\section{The experimental analysis}

In view of college students, they were in anaerobic and aerobic exercise test by contrast. Firstly,we tested the body in fundamental condition as shown in Table 1.We selected two classes of students who basically have no obvious difference physical condition. Table 1 is in the following range of indicators.

TABLE I. THE BASIC STATUS OF PHYSICAL TEST

\begin{tabular}{|l|l|l|c|}
\hline Height (cm ) & Age ( years) & body weight ( kg ) & BMI \\
\hline $160.02 \pm 6.29$ & $22 \pm 2.3$ & $63.22 \pm 6.24$ & $23.9 \pm 5.03$ \\
\hline
\end{tabular}

From Table 1 and Figure 1,we can see that the physical quality of the testers in class A and class $\mathrm{B}$ basically changed after anaerobic and aerobic exercise, except height is the basic fixed value, weight is reduced, and the BMI value was reduced. The description of the motion of the physical condition improved.

From Table 2, it can clearly see that the basic physical qualities of the testers of Class A, B changed differently after the anaerobic and aerobic exercise for the body state brings after aerobic exercise for the physical changes relative anaerobic exercise is more obvious, and the physical 
quality index, calm heart rate values and body weight, BMI value and vital capacity is 0.01 in the $\mathrm{P}<$ level has significant difference. Height and standing long jump is 0.05 in the $\mathrm{P}>$ level has significant difference. The A class quiet when the value of heart rate is $79.66 \pm 7.26$ range, but for the $\mathrm{B}$ class was $66.74 \pm 6.7$, and weight class B than the A class to drop more, vital capacity, standing long jump will increase more, but the difference of the distance is not large, it is also based on exercise the time period is relatively short reason.

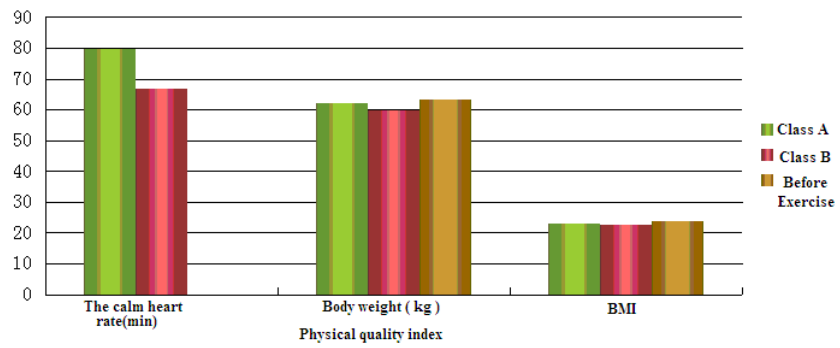

Figure 1. The physical quality changes of Class A, B before and after test TABLE II. THE BASIC PHYSICAL QUALITY COMPARISON TABLE OF CLASS A, B

\begin{tabular}{|c|c|c|c|c|c|c|}
\hline & $\begin{array}{l}\text { the calm } \\
\text { heart rate }(\mathrm{min})\end{array}$ & $\begin{array}{l}\text { Heigh } \\
(\mathbf{c m})\end{array}$ & $\begin{array}{c}\text { body } \\
\text { weight } \\
(\mathrm{kg})\end{array}$ & BMI & $\begin{array}{c}\text { Spiro } \\
\text { metry } \\
(\mathrm{ml})\end{array}$ & $\begin{array}{l}\text { the standing } \\
\text { long jump } \\
\text { (cm) }\end{array}$ \\
\hline Class A & $\begin{array}{l}79.66 \\
\pm 7.26 \\
\end{array}$ & $\begin{array}{l}160.02 \\
\pm 6.29 \\
\end{array}$ & $\begin{array}{l}62.34 \\
\pm 5.13\end{array}$ & $\begin{array}{l}23.2 \\
\pm 6.03 \\
\end{array}$ & $\begin{array}{l}2294.86 \\
\pm 321\end{array}$ & $\begin{array}{l}169.15 \\
\pm 12.71 \\
\end{array}$ \\
\hline Class B & $\begin{array}{l}66.74 \\
\pm 6.7 \\
\end{array}$ & $\begin{array}{l}160.02 \\
\pm 6.28 \\
\end{array}$ & $\begin{array}{l}59.89 \\
\pm 4.56 \\
\end{array}$ & $\begin{array}{l}22.9 \\
\pm 1.77 \\
\end{array}$ & $\begin{array}{l}2401.62 \\
\pm 321\end{array}$ & $\begin{array}{l}171.14 \\
\pm 15.44 \\
\end{array}$ \\
\hline $\mathrm{P}$ & $\begin{array}{l}\mathrm{P}< \\
0.01 \\
\end{array}$ & $\begin{array}{l}\mathrm{P} \\
>0.05\end{array}$ & $\begin{array}{l}\mathrm{P}< \\
0.01 \\
\end{array}$ & $\begin{array}{l}\mathrm{P}< \\
0.01 \\
\end{array}$ & $\begin{array}{l}\mathrm{P}< \\
0.01 \\
\end{array}$ & $\begin{array}{l}\mathrm{P}> \\
0.05\end{array}$ \\
\hline
\end{tabular}

From Table 3 classes of testing various body circumference contrast obtained, through anaerobic and aerobic exercise for all body circumference produces different changes. Waist circumference and the largest bust is 0.05 in the $\mathrm{P}<$ level has significant difference, hip and minimum bust is 0.01 in the $\mathrm{P}<$ level, bust in $\mathrm{P}>0.05$ level has significant difference.

TABLE III. THE VARIOUS BODY CIRCUMFERENCE CONTRAST TABLE IN CLASS A, B (CM )

\begin{tabular}{|l|l|l|l|l|l|}
\hline & \multicolumn{1}{|c|}{$\begin{array}{c}\text { Waist circum } \\
\text { ference }\end{array}$} & \multicolumn{1}{|c|}{$\begin{array}{c}\text { Hip circum } \\
\text { ference }\end{array}$} & $\begin{array}{c}\text { Chest circum } \\
\text { ference }\end{array}$ & $\begin{array}{c}\text { Maxi mum } \\
\text { bust }\end{array}$ & \multicolumn{1}{c|}{$\begin{array}{c}\text { Mini mum } \\
\text { bust }\end{array}$} \\
\hline \multirow{2}{*}{ Class A } & 74.00 & 98.44 & 95.27 & 99.26 & 93.20 \\
& \pm 8.55 & \pm 9.12 & \pm 6.32 & \pm 12.44 & \pm 11.33 \\
\hline \multirow{2}{*}{ Class B } & 75.43 & 96.41 & 95.55 & 101.57 & 91.10 \\
& \pm 7.88 & \pm 7.12 & \pm 7.41 & \pm 11.29 & \pm 11.74 \\
\hline $\mathrm{P}$ & $\mathrm{P}<0.05$ & $\mathrm{P}<0.01$ & $\mathrm{P}>0.05$ & $\mathrm{P}<0.05$ & $\mathrm{P}<0.01$ \\
\hline
\end{tabular}

From Table 3 and Figure 2, the body surround degree are different in Class A, B after aerobic and anaerobic exercise, which has correspondingly reduced.This fully illustrated that anaerobic and aerobic exercise has a slimming effect, but the degree of weight loss is not the same[9,10]. In addition to waist trend some difference, class A of the hips, bust circumference ,the maximum and minimum circumference is B class testing of corresponding circumference numerical ones, which also reflected the aerobic exercise for each human circumference relative anaerobic exercise to uniformly effective methods. While anaerobic exercise can only be aimed at a specific site. Class A are tested by waist with the mean $74 \mathrm{~cm}$, compared to B class $75.43 \mathrm{~cm}$, it is small.It also explains that the anaerobic exercise is also equivalent to that of the body for exercise, which is than aerobic exercise effect obviously[11]. But relative to the character of aerobic exercise on human body circumference reduction, it is balanced condition that aerobic exercise can improve the human body in the form of beauty.

TABLE IV. A, B TWO TESTERS AFTER MUSCULAR EXERCISE EACH INDEX CONTRAST
\begin{tabular}{|l|l|l|}
\hline & ClassA( anaerobic ) & Class B ( aerobic) \\
\hline Lactic acid value m mol/L & 13.62 & 3.67 \\
\hline Blood glucose value $\mathrm{m} \mathrm{mol} / \mathrm{L}$ & 9.3 & 5.45 \\
\hline Lactate dehydrogenase U/L & 331 & 290 \\
\hline Creatine kinase value U/L & 1341 & 1501 \\
\hline Alkaline phosphatase values U/L & 121 & 100 \\
\hline Myoglobin values $\mu \mathrm{g} / \mathrm{L}$ & 218.2 & 449.7 \\
\hline Hemoglobin g/L & 162 & 161 \\
\hline
\end{tabular}


From Table 4 and Figure 3, relative to the B class of aerobic exercise, we can see that Class A anaerobic movement is larger in lactate, blood glucose value, value, value of lactate dehydrogenase and alkaline phosphatase values. While the creatine kinase and myoglobin values are compared to class B test results,it must be small[12,13]. But the various indexes have some differences. Either anaerobic or aerobic exercise, muscles of the body each index has some changes. But the degree of change is not the same. The creatine kinase and myoglobin values values are mainly more significant.

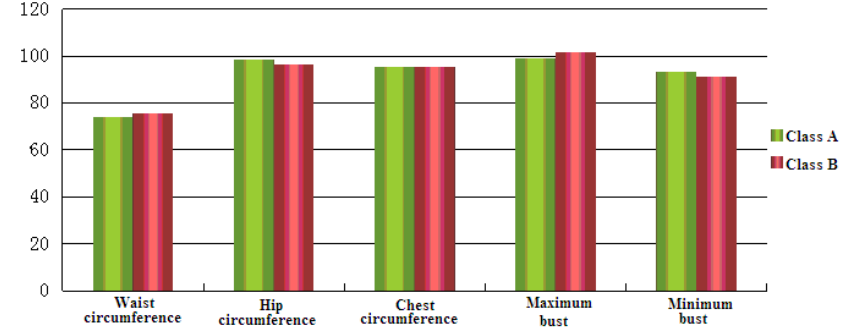

Figure 2. The body circumference degree comparison of Class A, B

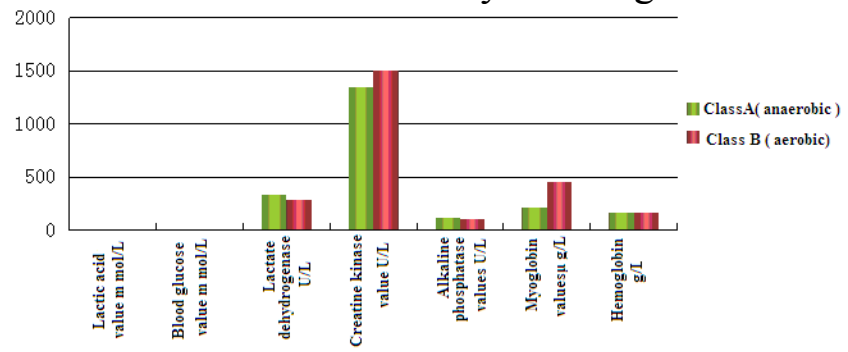

Figure 3. The index changes in contrast of Class A, B after muscular exercise

\section{Conclusion}

The conditions of the testers are greatly improved after anaerobic and aerobic exercise,which enbodies on body condition, quality improvement, body calm heart rate value, various body circumference and so on.The weight have different degrees of decline.But relatively speaking, anaerobic exercise more focused on the physical strength and the training, and aerobic movement is more concerned on the term for a body of each index equilibrium exercise. However, anaerobic and aerobic exercise have certain effect on weight loss and the same degree of changes. From the health point of view,in order to prevent the occurrence of obesity, we need to strengthen long-term physical exercise.Relatively speaking, we adopt aerobic exercise from either time or intensity, which is more suitable for you, but we also want to personal physical fitness in the appropriate adjustments and changes.And a right position can strengthen anaerobic exercise, but also we should pay attention to the balance between work and rest.We should not be blind to the exercise, so as not to run counter to one's desire. In order to achieve the effect of reducing weight and staying healthy. We must pay attention to anaerobic and aerobic exercise combined with each other, so as to establish a good living habits, which can really improve our health.

\section{References}

[1] Sun Qingzhu.Let Shilin. Human physique measurement and evaluation. Higher education press, 2011 ( 7):12-16.

[2] Ye Chaoqun, Kang Yuhua.The diet control, exercise on obese immune effects. Journal of Beijing Teachers College, 2009(9):65-68.

[3] TaoYonggang. Body training on female university students' physique effect.Sports theory, 2011 (12): 196-197.

[4] ZhangKehong. National students physical and health education evaluation standard study. Hangzhou: Zhejiang University press, .2010:234-237.

[5] Li Wentao. The explosive force training best load. Sports science and technology, 2011 (12):67-69.

[6] Zhang Pinghua.The exercise training on female college students' heart rate, low body weight blood pressure.Journal of Hunan University of Science and Engineering,2010(9):39-41.

[7] Ministry of education.The State Sports General Administration. On the issuance of " Student Physique Healthy Standard ( Trial Scheme) " and "Student Physique Healthy Standard ( Trial Scheme) implementation measures ".2011:207-225

[8] International Life Science Society of China.China Office obesity Working Group joint data pooled analysis of cooperative group. China adult body mass index classification of recommendation. Chinese Journal of preventive medicine, 2011 ( 5): 49-50 